\title{
Soil Water Balance: A Computer Tool for Teaching Future Irrigation Managers
}

\author{
N. Z. Jovanovic and J. G. Annandale*
}

\begin{abstract}
Critical water shortage problems will face South Africa in the near future. It is extremely important to train future irrigation managers to apply new technologies to the solution of these problems. The Soil Water Balance (SWB) irrigation scheduling computer model was presented to 4 th-year agricultural students in the soil physics and irrigation courses at the University of Pretoria. The SWB model is a mechanistic, real time, user-friendly model, that predicts crop growth and the soil water balance from available crop management, soil, and weather data. It includes a stand-alone window in which the FAO (Food and Agricultural Organization) Penman-Monteith grass reference evapotranspiration can be calculated (ET $\mathbf{T}_{0}$ calculator). The objectives were to assess the effectiveness of a computer application as a teaching tool, to determine whether a complex integrated model (SWB) is more suitable for educational purposes than a simpler

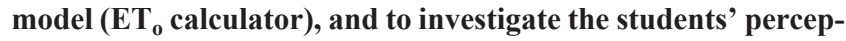
tion of the models. The exercise included a lecture where the theory was discussed, and the models were demonstrated making use of realistic examples. Optional homework exercises were then assigned and marked. The average score was $77.1 \% \pm 8.0 \%$ for the SWB homework, and $\mathbf{8 0 . 8 \%} \pm \mathbf{1 0 . 1 \%}$ for the $\mathrm{ET}_{\mathbf{0}}$ calculator. The simpler $\mathrm{ET}_{0}$ calculator appeared to be better understood than the more complex SWB. Several technical improvements were suggested by the students. Simple computer models are recommended for practical exercises at the end of each lecturing session. The demonstration of complex models integrating various lecturing sessions could then be made at the end of the course.
\end{abstract}

$\mathrm{S}_{\mathrm{art}}^{\mathrm{o}}$ OUTH AFRICA is one of the countries where water resources and supplies have already reached critically low levels, particularly in the developing rural communities. It is expected that, in the near future, these supplies will come under even more stress due to the growth in population and increasing water use per capita. It is therefore of great importance that the public be aware of the problem and informed of strategies to save water. The media, private business and government, as well as educational institutions at all levels, are currently involved in presenting the problem and possible solutions to the public.

Agriculture is an important economic activity in the country and is also the largest consumer of water. Water management extension programs may be improved in the future by providing educational resources to university students. The efficient management of water resources in agriculture is taught in several graduate and postgraduate courses at the University of Pretoria, in the Department of Plant Production and Soil Sci-

Dep. Plant Production and Soil Science, Univ. of Pretoria, 0001, Pretoria, South Africa. Received 29 Sept. 1998. *Corresponding author (annan@ scientia.up.ac.za).

Published in J. Nat. Resour. Life Sci. Educ. 29:15-22 (2000).

http://www.JNRLSE.org ence. Particular attention to the problem is given in courses where students are taught irrigation principles. It is essential that future irrigation specialists, extension officers, farmers, and consultants be trained in applying techniques oriented toward more efficient water use.

Managing irrigation water requires a quantitative description of the dynamic, complex soil-plant-atmosphere system. The most efficient way to investigate many of the What if? options available to the irrigation manager is through a computer model. The use of computers at higher educational institutions is increasing, particularly since information systems have become widely affordable. Computer tools are effective means of illustrating principles that are otherwise difficult to conceptualize, in particular because young people find them familiar and interesting. Furthermore, they give the opportunity of applying theoretical principles to actual management situations. Several studies have already been published on the use of computers as teaching tools (Cassel and Elrick, 1992; Hannaway et al., 1992; Cross, 1993; Kohut et al., 1993; Robinson and Schafer, 1993; Fermanian and Wehner, 1995; Scott and Smith, 1995). Ferguson and Chapman (1993) reported that computer applications helped the students to improve their grades. Michaels (1993) argued that new technologies encourage students to approach the problem in a fresh way, as they may have developed a pattern for their approach to a term paper, laboratory report, or class presentation. The use of computers as a teaching aid can also allow teachers to spend less time in preparing lectures (Cattle et al., 1995), and dedicate more time to research work.

In this study, the Soil Water Balance (SWB) irrigation scheduling computer model (Annandale et al., 1996a) was presented to undergraduate students in the GKD 329 soil physics and PGW 422 irrigation courses. The objectives were to familiarize them with the use of computers in problem solving, as well as to strengthen their understanding of some of the theoretical principles explained during the course. The SWB model integrally describes the soil-plant-atmosphere system and calculates a large number of soil water balance parameters for the specific input setting. It allows the user to choose parameter values before calculation and to simulate realistic scenarios. This should stimulate students to experiment with the various parameters to determine which have the greatest effect, and provide problem-solving management experience, which will help them in their professional employment. The development of problem-solving and critical-thinking skills were reported to be the basic educational needs in agriculture and natural resource management (Salvador et al., 1995).

Abbreviations: ADL, allowable depletion level; ADWC, air dry soil water content; $\mathrm{ET}_{\mathrm{o}}$, Penman-Monteith grass reference evapotranspiration; FAO, Food and Agricultural Organization; FC, field capacity; MB, mass balance; PET, potential evapotranspiration; $\mathrm{PWP}$, permanent wilting point; $\mathrm{RH}_{\text {max }}$, maximum relative humidity; $\mathrm{RH}_{\text {min }}$, minimum relative humidity; $\mathrm{SWB}$, Soil Water Balance model; SWD, soil water deficit; $\mathrm{T}_{\text {dry }}$, dry bulb temperature; $\mathrm{T}_{\max }$, daily maximum temperature; $\mathrm{T}_{\min }$, daily minimum temperature; $\mathrm{T}_{\mathrm{wet}}$, wet bulb temperature; VP, actual vapor pressure. 
A comprehensive review of agronomic models was published by Hanks and Ritchie (1991). Most of these models are lacking in user-friendliness. One of SWB's main strengths is that it is written in a user-friendly Windows 95 format. The self-explanatory graphics make it easy to apply in practice and a valuable addition to available educational material. The SWB model is being tested by some irrigation consultants and farmers in the country. The model includes a stand-alone window where the FAO (Food and Agricultural Organization, Rome, Italy) Penman-Monteith grass reference evapotranspiration $\left(\mathrm{ET}_{\mathrm{o}}\right)$ can be calculated.

The objectives of this study were (i) to assess the effectiveness of a computer application as a teaching tool; (ii) to determine whether a more complex model that gives an integrated description of a natural process, like SWB, is more suitable as a teaching tool than a simple model, like the $\mathrm{ET}_{\mathrm{o}}$ calculator, which describes only one part of the system; and (iii) to investigate the students' perception of, and possible recommendations for improvements in user-friendliness of the SWB model as a teaching tool.

\section{THEORETICAL OVERVIEW OF THE MODEL}

\section{Soil Water Balance Model}

The SWB model is a mechanistic, daily time step, generic crop growth model. It is based on the improved version of the soil water balance model described by Campbell and Diaz (1988). The multilayer soil component of the model ensures a realistic simulation of water infiltration and crop water uptake processes. A cascading soil water balance is used after canopy interception and surface runoff have been considered. Potential evapotranspiration (PET), adopted from internationally standardized FAO Penman-Monteith methodology (Allen et al., 1998), is calculated as a function of daily average air temperature, vapor pressure deficit, solar radiation, and wind speed. Potential evapotranspiration is divided into potential evaporation and potential transpiration by calculating canopy radiant interception from simulated leaf area (Ritchie, 1972). These represent the upper limits of evaporation and transpiration and the processes will only proceed at these rates if atmospheric demand is limiting. However, the supply of water to the soil surface or plant root system may be lim- iting. This is simulated in the case of soil water evaporation, by relating evaporation rate to the water content of the surface soil layer (Campbell and Diaz, 1988). In the case of transpiration, a dimensionless solution to the water potential based water uptake equation is used (Campbell and Norman, 1998). This solution has been shown to work extremely well by Annandale et al. (1996b). If actual transpiration is less than potential transpiration, the crop experiences stress and leaf area development is reduced. Crop transpiration is not calculated for the top soil layer, which is reserved for evaporation.

In $\mathrm{SWB}$, crop dry matter is accumulated in direct proportion to transpiration corrected for vapor pressure deficit (Tanner and Sinclair, 1983). The model also calculates radiation limited dry matter production (Monteith, 1977), and uses the lowest dry matter estimate. This dry matter is partitioned to roots, stems, leaves, and grains or fruits. Partitioning depends on crop phenology calculated with thermal time and modified by water stress. Required crop parameters include thermal time requirements and assimilate partitioning parameters. The SWB model includes a database of growth parameters for several commonly cropped species.

Essential input data are planting date, latitude, altitude, rainfall and irrigation water amounts, maximum and minimum daily temperatures, initial water contents of the soil layers, and two points on the water release curve, usually field capacity and wilting point. The SWB model uses a crop parameter, weather, field, water, and soil database, which negates the need to generate several ASCII files in a text editor to handle each simulation. Extensive use is made of graphics and several output variables can be graphically displayed. Crop growth variables and soil water balance components for each day of the simulation can also be seen in a result table.

\section{ET $_{\text {o }}$ Calculator}

The SWB model uses weather input data to calculate $\mathrm{ET}_{\mathrm{o}}$. This can also be calculated in a separate window $\left(\mathrm{ET}_{\mathrm{o}}\right.$ calculator, Fig. 1), without having to run the full SWB model. The $\mathrm{ET}_{\mathrm{o}}$ calculator computes $\mathrm{ET}_{\mathrm{o}}$ using the same procedure used in SWB. Essential input data are: date, daily maximum $\left(\mathrm{T}_{\max }\right)$ and minimum temperature $\left(\mathrm{T}_{\min }\right)$, latitude, hemisphere, and elevation. In the absence of measured data, solar radiation is calculated from maximum and minimum temperature, as well

4h. FAO ETo calculator $-4 \mid x$

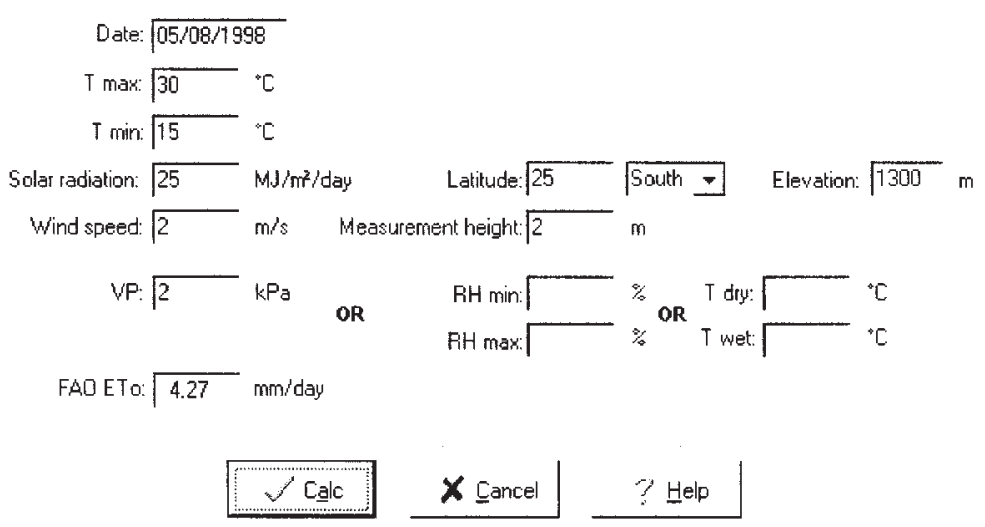

Fig. 1. Screen printout of example of the Penman-Monteith grass reference evapotranspiration $\left(\mathbf{E T}_{\mathbf{0}}\right)$ calculator.

16 • J. Nat. Resour. Life Sci. Educ., Vol. 29, 2000 
as latitude and altitude (Allen, 1995). If wind speed is not available, the $\mathrm{ET}_{\mathrm{o}}$ calculator assumes an average wind speed of $2 \mathrm{~m} / \mathrm{s}$ (Allen et al., 1998). If wind speed is not measured at a 2-m height, the measurement height is entered and wind speed is normalized using the logarithmic vertical profile function recommended by Allen et al. (1989). If not measured, the actual vapor pressure (VP) is calculated from measured minimum $\left(\mathrm{RH}_{\text {min }}\right)$ and maximum relative humidity $\left(\mathrm{RH}_{\max }\right)$ (Allen et al., 1998), and if that is not available, from measured dry bulb $\left(\mathrm{T}_{\text {dry }}\right)$ and wet bulb temperature $\left(\mathrm{T}_{\text {wet }}\right)$ (Bosen, 1958). If no atmospheric vapor measurements are available, the $\mathrm{ET}_{\mathrm{o}}$ calculator assumes $T_{\text {min }}$ reaches dew point, and VP is equal to the saturated VP at $\mathrm{T}_{\text {min }} ; \mathrm{ET}_{\mathrm{o}}$ is calculated by clicking on the bottom left icon.

\section{Software Applications and Availability}

The SWB model is available for use with Windows 95 on an IBM-PC or compatible computer. The minimum requirement is $16 \mathrm{Mb}$ RAM. The time required to complete a seasonal simulation is 3 to $5 \mathrm{~s}$ on a Pentium 166. The program is supplied in executable code on 3.5-inch disks or CD, with a quick reference user guide manual making extensive use of graphics. Copies of the program are available through John G. Annandale, Dep. of Plant Production and Soil Science, Univ. of Pretoria, 0001 Pretoria, South Africa (email address: annan@scientia.up.ac.za). Reproduction and shipping costs are payable. The SWB irrigation scheduling model, including the $\mathrm{ET}_{\mathrm{o}}$ calculator, was not specially modified or adapted for the purpose of classroom presentation.

\section{METHODS}

\section{The Soil Water Balance Model Classroom Demonstration}

The theoretical background of SWB was discussed in a three-period classroom demonstration (each period was 50 min). Particular attention was given to the concept and procedures describing the atmospheric evaporative demand-soil water supply limited root water uptake. Students were made aware that high-frequency irrigations reduce the risk of crop water stress, but also reduce crop water use efficiency due to an increase in direct soil water evaporation and less effective use of rainfall. The effect of crop stress on transpiration and yield was explained, as well as the dynamics of the soil water balance components during the growing season.

Classroom demonstrations and the use of examples to quantify results are excellent tools to inspire and motivate students through direct visual observation (Butters and Bandaranayake, 1993). The SWB model was demonstrated using a data projector. The students were shown how to enter input data, run the model, and see the results both in graphic and table format. A simulation was done for dryland babala [pearl millet, Pennisetum glaucum (L.) R. Br., cv. SA Standard] grown at Bethal (Mpumalanga Province, South Africa). Theoretical principles were discussed using graphical output. A printout of the soil water balance graph is shown in Fig. 2. In the top half of the graph, black histogram bars represent rainfall amounts. No irrigations, which are represented with nonfilled histogram bars, are used in this example. In the bottom half of the graph, the solid line with bold sections represents the soil water deficit (SWD), and the other line recommended allowable depletion level (ADL). In Fig. 2, the SWD line is thin on days when the ratio of actual to potential transpiration is $\geq 0.95$ (atmospheric evaporative demand limited crop water use), and thicker when this ratio is $<0.95$ (soil water supply limited root uptake, and therefore water stress conditions). On the computer screen, the SWD line appears thin and blue when the ratio of actual to potential transpiration is $\geq 0.95$, and thick and red when this ratio is $<0.95$. The ADL is calculated as a function of root depth, soil physical properties, and crop water stress tolerance for the particular growth stage. In the top right corner, the soil water deficit at the end of the simulation is reported. The following information is displayed

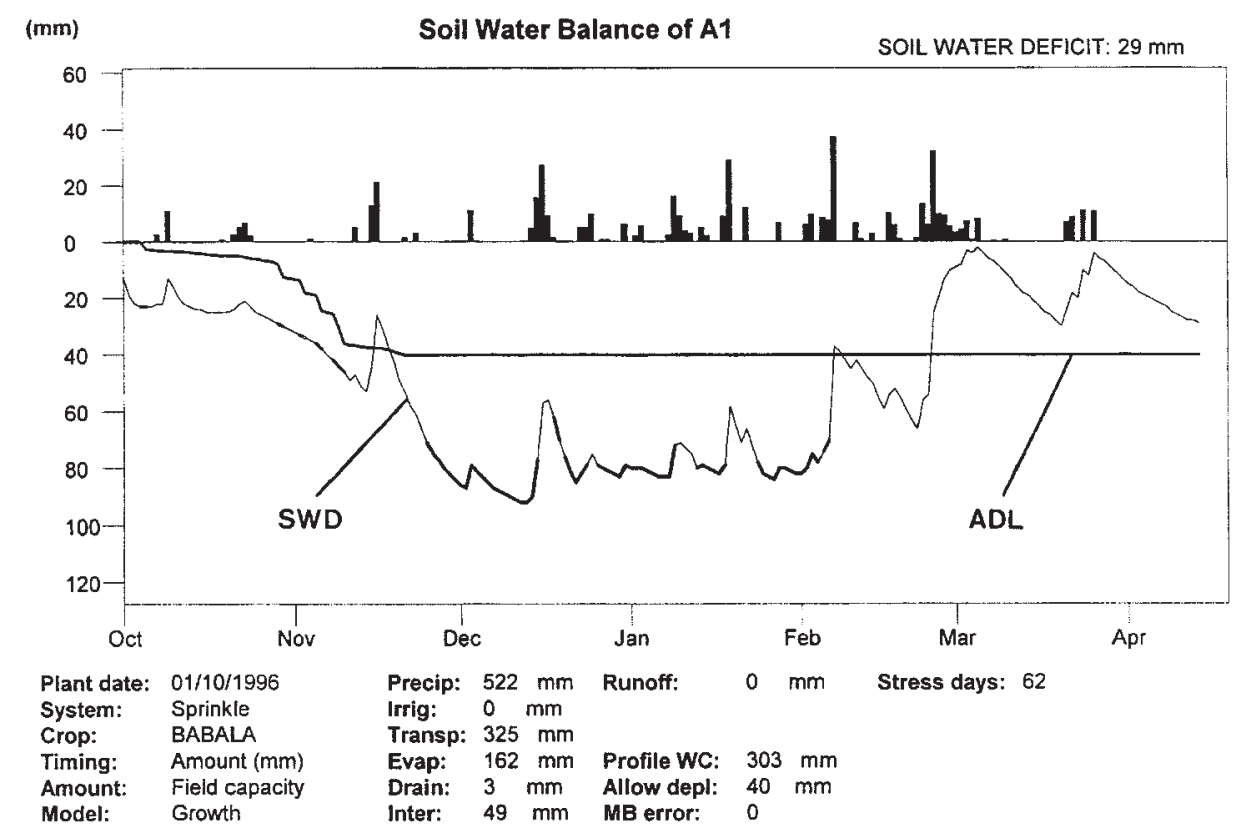

Fig. 2. Printout of soil water balance simulation for babala [pearl millet, Pennisetum glaucum (L.) R. Br., cv. SA Standard] grown at Bethal (South Africa). Soil water deficit (SWD), allowable depletion level (ADL), and rainfall (black histogram bars) are shown on the graph. 
below the graph: planting date, irrigation system used, crop simulated, recommended irrigation timing and amount, and type of model used. Calculated seasonal precipitation, irrigation, transpiration, evaporation, drainage, canopy interception, runoff, number of stress days, profile water content at field capacity, and allowable depletion level at the end of the simulation are also shown. The mass balance error (MB error) is used to check possible numerical errors in the simulation.

There are several reasons why an estimation procedure may perform poorly. Insect or herbicide damage may, for example, delay canopy development. As this is not accounted for in the model, a larger canopy and drier profile than actually exists will be forecast. It is possible to enter measured soil water at any stage during the season, and the model will bring the simulation in line. Whenever a correction to the soil water content is entered, a mass balance error will appear in the soil water balance graph (Fig. 2).
Several other variables can be graphically displayed. Figure 3 shows the daily evaporation and transpiration output graph. Evaporation from the soil surface is the dominant process in the first part of the season when the crop canopy is still small. By increasing the canopy cover, crop transpiration becomes the dominant process. Fluctuations in evaporation and transpiration depend on atmospheric evaporative demand, rainfall pattern, and soil water supply. Figure 4 shows water content at several soil profile depths. Layer depths are indicated in the top right corner of each graph. Field capacity (FC), permanent wilting point (PWP), and air dry water content (ADWC) are shown in the top layer graph. Water balance in the topsoil layer is the most dynamic due to infiltration and evaporation. Fluctuations in soil water content decrease in deeper layers, where the root system is less dense.

The use and purpose of SWB was discussed at the end of the classroom demonstration. The SWB model is a mecha-

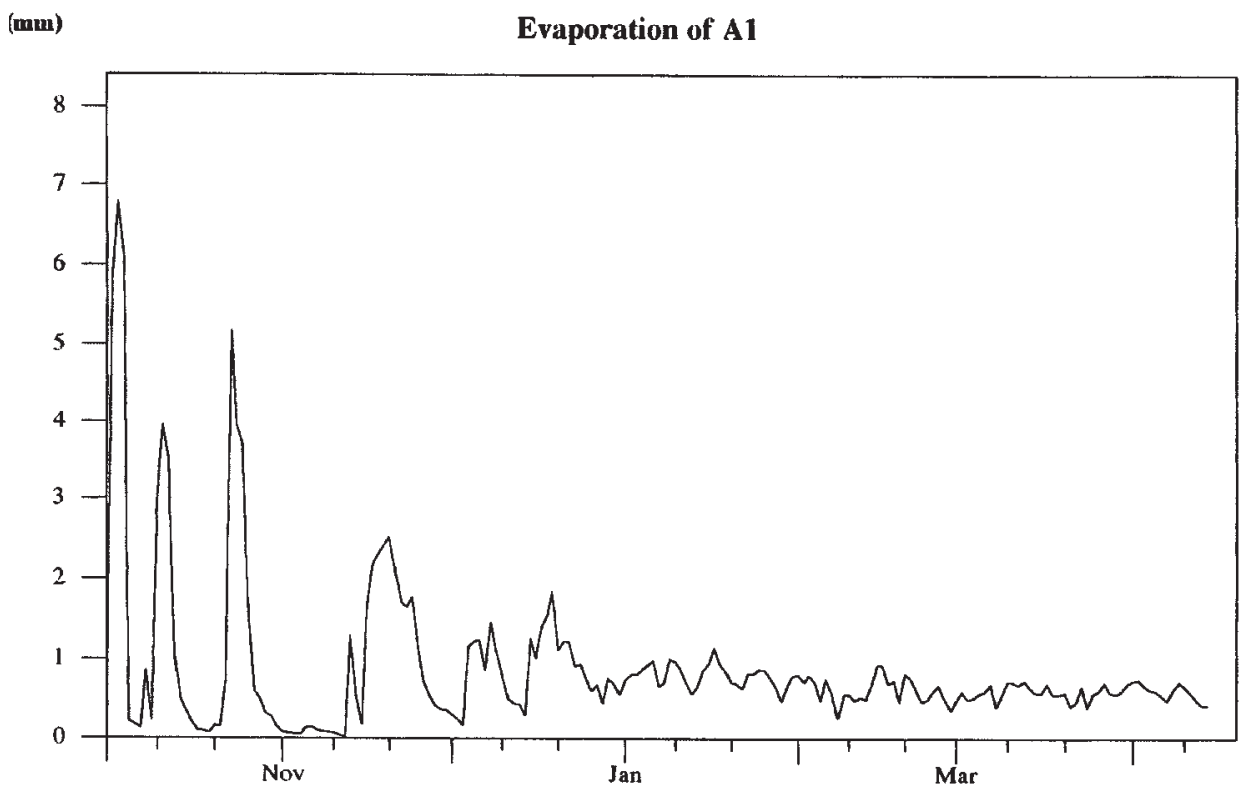

(mm)

Transpiration of A1

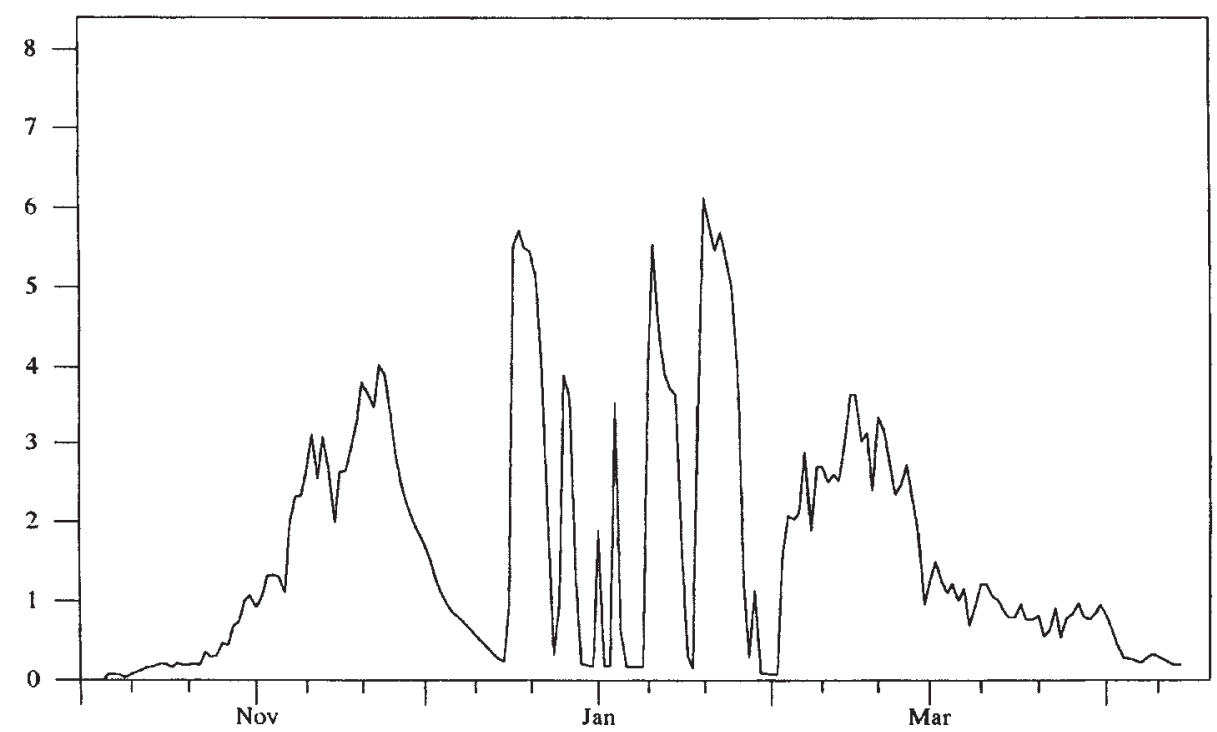

Fig. 3. Printout of evaporation and transpiration simulation for babala [pearl millet, Pennisetum glaucum (L.) R. Br., cv. SA Standard] grown at Bethal (South Africa).

18 • J. Nat. Resour. Life Sci. Educ., Vol. 29, 2000 
nistic, and therefore universally valid approach for estimating crop water use, and has several advantages over more empirical methods often used. Using thermal time to describe crop development removes the need to use different crop factors for different planting dates and regions. Splitting evaporation and transpiration solves the problem of taking irrigation frequency into account. Deficit irrigation strategies, where water use is supply limited, can also be more accurately described. The effect of water stress on canopy cover is also taken into account. User-friendly models can make accurate, high technology approaches to irrigation scheduling feasible on farm. This approach can reduce the costs and increase the benefits of irrigation scheduling. Potential users of the SWB model are not only researchers, but include farmers, irrigation extension officers, and consultants.

\section{ET $_{0}$ Calculator Classroom Demonstration}

The $\mathrm{ET}_{\mathrm{o}}$ calculator was discussed in a one-period classroom demonstration with the aid of a data projector. The equations used to calculate $\mathrm{ET}_{\mathrm{o}}$ were presented, and a few calculations were made to explain how $\mathrm{ET}_{\mathrm{o}}$ varies when different input data are used.

The applications of the $\mathrm{ET}_{\mathrm{o}}$ calculator were then discussed. If empirical crop factors are known, the $\mathrm{ET}_{\mathrm{o}}$ calculator can be easily applied in practice to determine potential daily crop water use (Doorenbos and Pruitt, 1976) to calculate the soil water balance. The same potential users of SWB could use the $\mathrm{ET}_{\mathrm{o}}$ calculator to schedule irrigations. This method, however, does not account for irrigation frequency and soil water supply limitations, and empirical crop factors are often difficult to obtain.

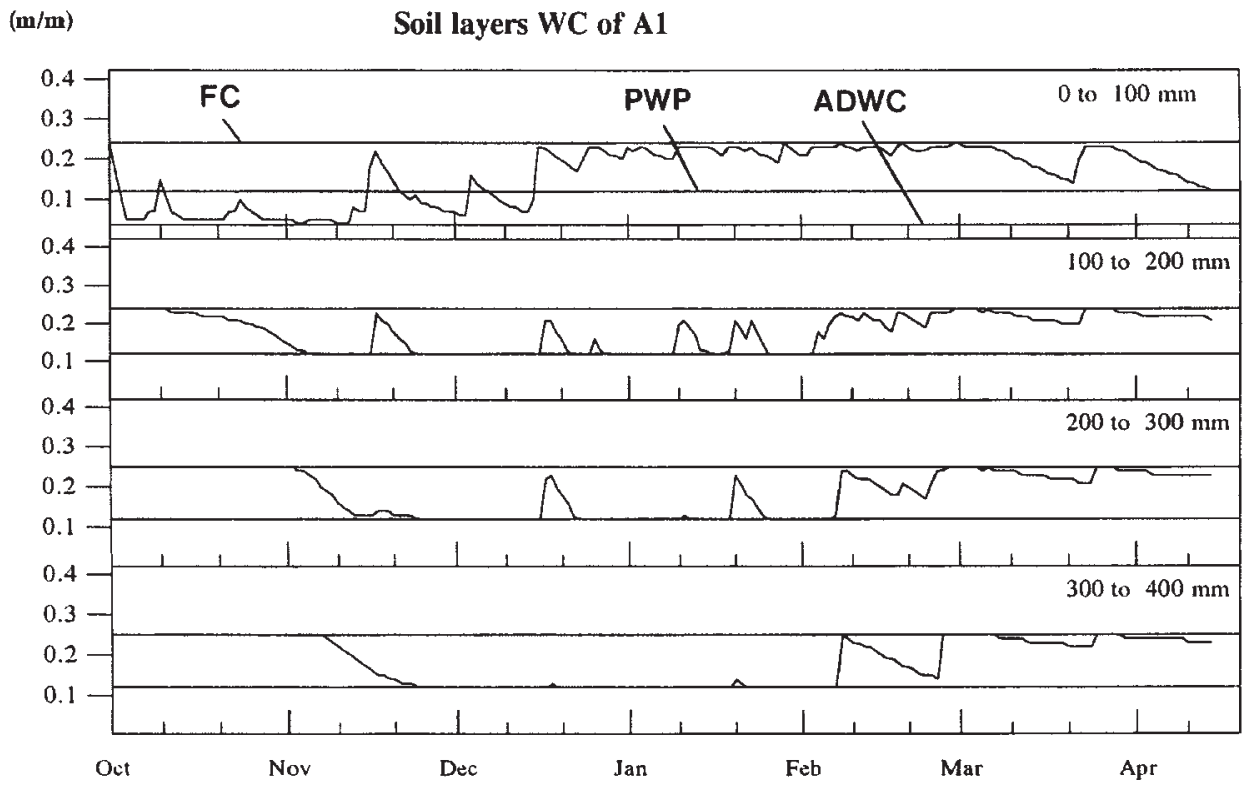

$(\mathbf{m} / \mathbf{m}) \quad$ Soil layers WC of A1

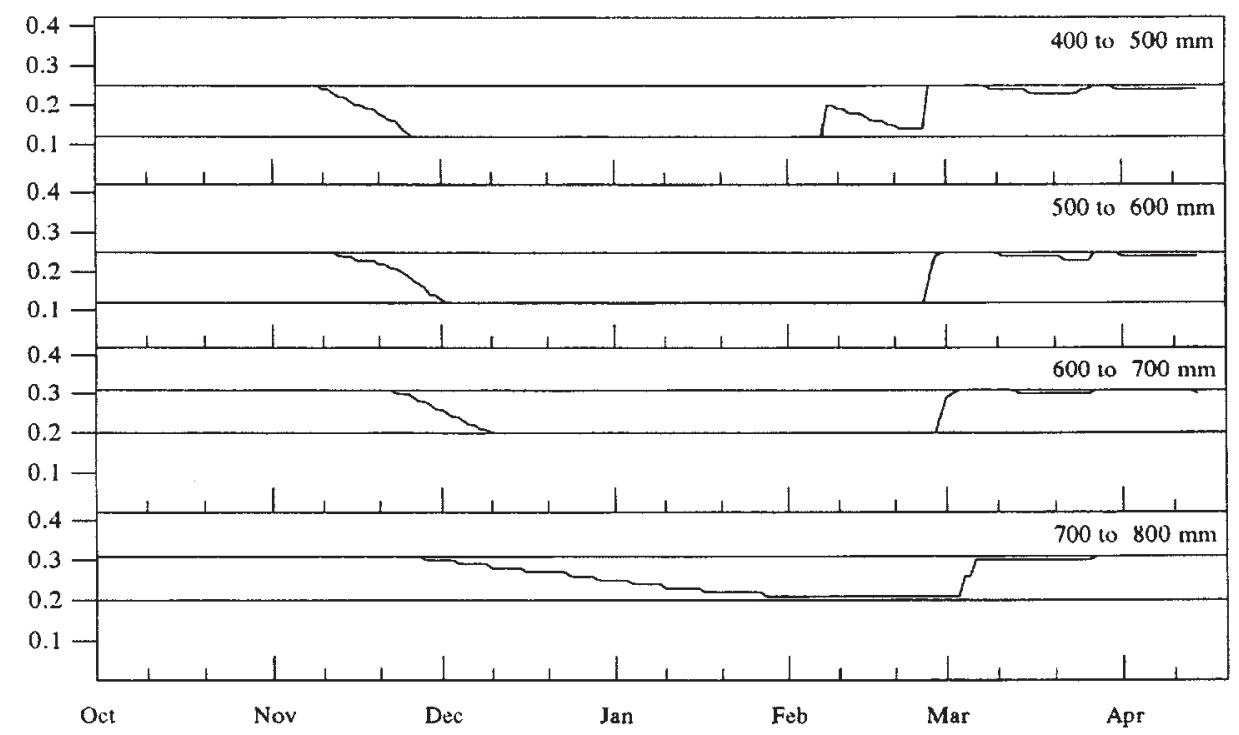

Fig. 4. Printout of soil water content simulation per layer, for babala [pearl millet, Pennisetum glaucum (L.) R. Br., cv. SA Standard] grown at Bethal (South Africa). Field capacity (FC), permanent wilting point (PWP), and air dry soil water content (ADWC) are shown on the graph. 
Table 1. Homework questions, points assigned, and students' score for the Soil Water Balance (SWB) model exercise.

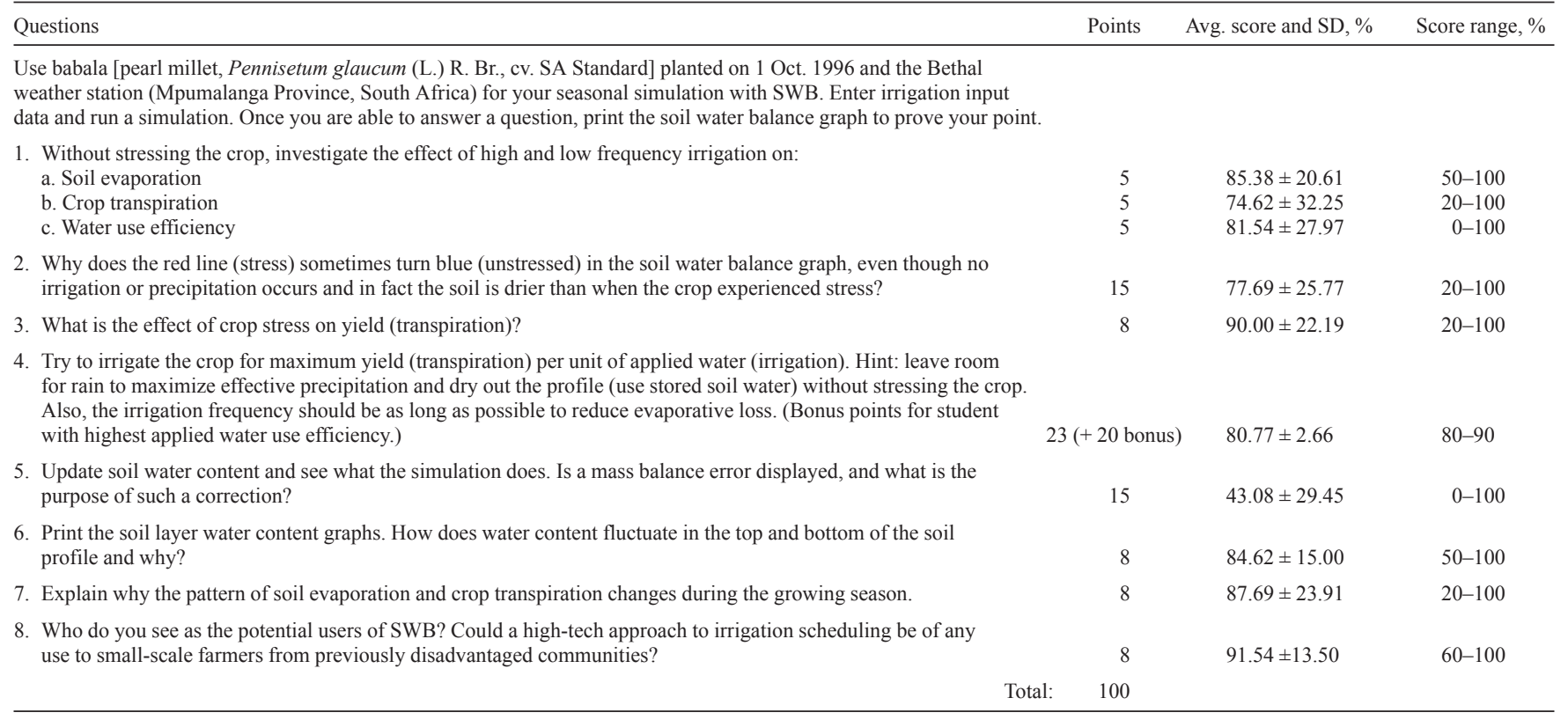

\section{Homework Exercises}

Optional homework exercises were assigned for the SWB model and the $\mathrm{ET}_{\mathrm{o}}$ calculator. The questions are summarized in Tables 1 (SWB) and 2 (ET, calculator). Such homework exercises should stimulate individualized learning (Kolb, 1984), allowing the students to carry out scenario modeling with no predetermined outcome (e.g., one simulation data set for babala grown in Bethal, and variable irrigation input data). The tasks were then to interpret output results, logically explain a process, or defend an argument.

Hints for the homework questions were given during the classroom demonstrations. The students were asked to use the study material from previous course work. In addition, study material with a detailed description of SWB was distributed. The set of equations used in the $\mathrm{ET}_{\mathrm{o}}$ calculator was also distributed as study material in written format with references. Copies of the models were made available on 3.5-inch disks and in the students' computer room. A quick reference guide manual making extensive use of graphics was made available to facilitate familiarization with the models. The students were given $2 \mathrm{wk}$ to complete the homework and return the answers.

\section{Students' Perception Questionnaire}

A questionnaire was also distributed to the students to determine whether the two models, in combination with the users guide manual, were user-friendly. It was also interesting to see, from the students' point of view, if the computer exercises helped them to better understand the topics covered in the courses. The questions for the students' evaluation are summarized in Table 3 . The students were also asked to indicate how many hours they spent with the homework. The authors were very open to any suggestions or criticism.

\section{RESULTS \\ Homework Exercises}

Thirteen of 21 students returned the homework exercises. These were marked and the results were statistically processed. Statistical results obtained for each homework exercise are

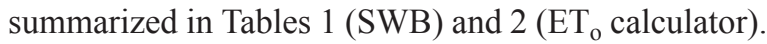

Only one of the questions presented a particular problem for the students; that was Question 5 of the SWB homework (Table 1). Many students answered that mass balance error output is used to verify the correctness of model predictions and to quantify the error committed by the model. This is one of the purposes of mass balance calculation, but not the main reason for updating model simulations with measured data. In fact, the model is very unlikely to compute a value for a variable that is exactly equal to the measurement. The mass balance error is primarily used to verify the numerical correctness of the model. Computer models operated from offices are not supposed to completely substitute field measurements. They could, however, facilitate management by making field visits less frequent.

High scores were achieved by students for the first and second $\mathrm{ET}_{\mathrm{O}}$ calculator homework questions (Table 2). The average percentage was lower for the third homework question, which required a detailed explanation of the theory underlying the estimation of solar radiation and VP from available input data. A low score was observed on average for the fourth homework question, indicating that students did not properly comprehend the purpose, as well as the advantages and disadvantages of empirical and mechanistic models.

Statistical analyses of the homework results were also carried out for each student. None of the students had a score lower than $60 \%$, which was arbitrarily assumed to be the pass mark. The lowest score was $63.2 \%$ for SWB and $60.6 \%$ for 
Table 2. Homework questions, points assigned, and students' score for the exercise on the Penman-Monteith grass reference evapotranspiration $\left(\mathbf{E T}_{0}\right)$ calculator.

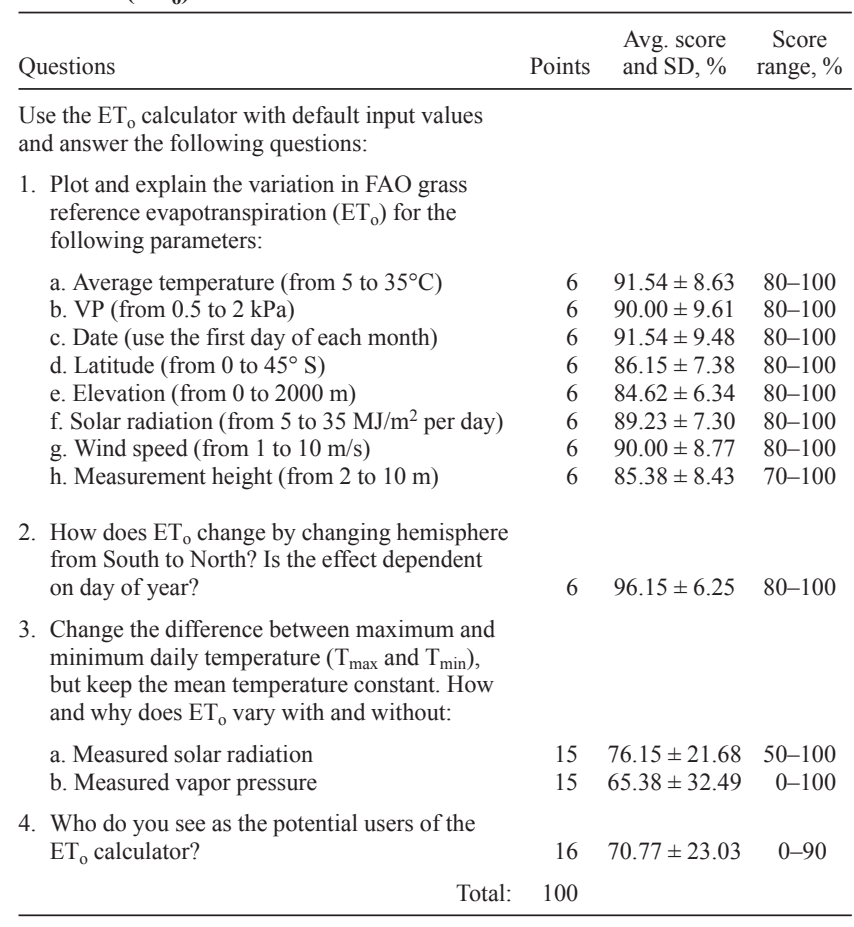

the $\mathrm{ET}_{\mathrm{o}}$ calculator homework. The highest scores were $90.8 \%$

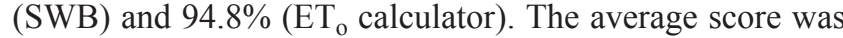
$77.1 \% \pm 8.0 \%$ for the SWB homework, and $80.8 \% \pm 10.1 \%$ for the $\mathrm{ET}_{\mathrm{o}}$ calculator.

\section{Students' Perception Questionnaire}

Eight of 13 students who did the homework exercises returned the evaluation questionnaire. The students spent on average $3.7 \mathrm{~h}$ (range 1.5-6 h) working on SWB and $1.5 \mathrm{~h}$ (range 1-2 h) on the $\mathrm{ET}_{\mathrm{o}}$ calculator. The number of hours indicated that the homework load was not excessive.

The results of the survey are summarized in Table 3 . The perception was generally positive. Both models helped students to better understand the topics. The students clearly indicated that the $\mathrm{ET}_{\mathrm{o}}$ calculator is simpler than SWB. The time required to run a simulation with SWB (15-20 s on a 486 DX66 computer) appeared to be too long when compared with the $\mathrm{ET}_{\mathrm{o}}$ calculator, which provides immediate feedback. One student indicated that "modeling exercises should be carried out at the end of a particular topic in a course in order to further the understanding of the subject". Some students did not use the model manual. This is not seen as a setback, but indicates that the models are user-friendly and accessible.

The students suggested the introduction of help screens that could show the user how to measure input parameters required by the models, and the equations used to calculate some of the output variables. Other technical suggestions included the automatic scaling of output graphs, the output of water use efficiency for seasonal evaluation of the user's irrigation scheduling, and the introduction of examples of how to run simulations for a specific crop. It was also suggested to include options for planning of irrigations by making use of historic weather data.
Table 3. Students' perception questionnaire.

\begin{tabular}{|c|c|c|c|}
\hline \multirow[b]{2}{*}{ Questions } & \multicolumn{3}{|c|}{ Answers } \\
\hline & Positive & Indecisive & Negative \\
\hline $\begin{array}{l}\text { 1. Did you find the Soil Water Balance (SWB) } \\
\text { model easy to use? }\end{array}$ & 4 & 4 & 0 \\
\hline $\begin{array}{l}\text { 2. Did you find the Penman-Monteith grass reference } \\
\text { evapotranspiration }\left(\mathrm{ET}_{\mathrm{o}}\right) \text { calculator easy to use? }\end{array}$ & 8 & 0 & 0 \\
\hline $\begin{array}{l}\text { 3. Did the graphics of SWB add to your understanding } \\
\text { of the behavior of the soil-plant-atmosphere } \\
\text { continuum? }\end{array}$ & $\lg$ & 1 & 0 \\
\hline $\begin{array}{l}\text { 4. Did the } \mathrm{ET}_{\mathrm{o}} \text { calculator assist you in understanding } \\
\text { the dynamics of atmospheric evaporative demand? }\end{array}$ & 8 & 0 & 0 \\
\hline $\begin{array}{l}\text { 5. Should user-friendly models like SWB and the } \\
\mathrm{ET}_{\mathrm{o}} \text { calculator be used as teaching tools? }\end{array}$ & 6 & 2 & 0 \\
\hline 6. Were the graphics in the manual helpful? & 4 & 1 & $3 \dagger$ \\
\hline 7. Was the explanatory text of the manual helpful? & 2 & 2 & $4 \dagger$ \\
\hline
\end{tabular}

$\dagger$ Not helpful or not used.

\section{CONCLUSIONS AND RECOMMENDATIONS}

The SWB computer model is a useful tool for providing instruction on the soil-plant-atmosphere system to students with diverse academic backgrounds and career orientations. The method, which requires only a computer and data projector, can be easily used in other courses and environments. It can also be beneficial for model developers to test the userfriendliness of models. The classroom demonstrations are easy to set up and can be conducted during the lecture period. The SWB model can be used for theoretical lessons, as well as to create homework assignments, provided that questions and explanations are carefully developed around known topics. Students who have not mastered the topic can be easily identified and the instructor can provide additional assistance according to individual needs. Additionally, more material can be covered in a given amount of time compared with traditional teaching methods.

Although not all students returned their homework, the computer exercise with SWB and the $\mathrm{ET}_{\mathrm{o}}$ calculator appeared to be successful in terms of students' interest, understanding of the subject, and development of problem-solving skills. For a proper and independent evaluation of the models as instructional tools, however, we recommend assigning the same homework before and after the demonstration. Alternatively, two different populations could be evaluated, one making use of the model and the other not using it.

Results of the homework and the students' evaluation indicated that a simpler computer model describing a portion of the system was more effective as a teaching tool than a complex mechanistic model. Several simple modules describing different components of the soil water balance (e.g., runoff, canopy interception, infiltration, drainage, evaporation, transpiration) could be compiled and presented to the students during the course. At the end of the course, a model that integrates these components could be finally demonstrated to synthesize the concepts.

Students' suggestions will be used to improve the technical aspects and functionality of the models, and the method of presentation. In particular, we recommend carrying out the practical modeling session immediately after the related lecture session has been completed. More time should be dedicated to explain the general principles and purpose of 
mechanistic and empirical models, and the estimates incorporated in the outputs. One or more examples of how to run simulations for a specific crop should be included in the user guide manual or online help screens should be compiled.

\section{REFERENCES}

Allen, R.G. 1995. Evaluation of procedures for estimating grass reference evapotranspiration using air temperature data only. FAO/AGL, Rome, Italy.

Allen, R.G., M.E. Jensen, J.L. Wright, and R.D. Burman. 1989. Operational estimates of evapotranspiration. Agron. J. 81:650-662.

Allen, R.G., L.S. Pereira, D. Raes, and M. Smith. 1998. Crop evapotranspiration. Guidelines for computing crop water requirements. FAO Irrigation and Drainage Pap. 56. FAO, Rome, Italy.

Annandale, J.G., N. Benadè, A.J. van der Westhuizen, and G.S. Campbell. 1996a. The SWB (Soil Water Balance) irrigation scheduling model. p. 944-949. In C.R. Camp et al. (ed.) Evapotranspiration and irrigation scheduling. Proc. Int. Conf., San Antonio, TX. 3-6 Nov. 1996. ASAE, St. Joseph, MI.

Annandale, J.G., A.J. van der Westhuizen, and F.C. Olivier. 1996b. Die fasilitering van tegnologie oordrag deur verbeterde besproeiigsriglyne vir groente en 'n meganistiese gewasmodeleringsbenadering. Rep. 476/1/96. Water Res. Commission, Pretoria, South Africa.

Bosen, J.F. 1958. An approximation formula to compute relative humidity from dry bulb and dew point temperatures. Monthly Weather Rev. 86(12):486.

Butters, G.L., and W. Bandaranayake. 1993. Demonstrations in solute transport using dyes: I. Procedures and results. J. Nat. Resour. Life Sci. Educ. 22:121-125.

Campbell, G.S., and R. Diaz. 1988. Simplified soil-water balance models to predict crop transpiration. In F.R. Bidinger and C. Johansen (ed.) Drought research priorities for the dryland tropics. ICRISAT, India.

Campbell, G.S., and J.M. Norman, 1998. An introduction to environmental biophysics. 2nd ed. Springer-Verlag, New York.

Cassel, D.K., and D.E. Elrick. 1992. Using the software package "MathCAD" as a tool to teach soil physics. J. Nat. Resour. Life Sci. Educ. 21:74-78.
Cattle, S.R., A.B. McBratney, and D.B. Yates. 1995. The soil stack: An interactive computer program describing basic soil science and soil degradation. J. Nat. Resour. Life Sci. Educ. 24:33-36.

Cross, T.L. 1993. AgVenture: A farming strategy computer game. J. Nat. Resour. Life Sci. Educ. 22:103-107.

Doorenbos, J., and W.O. Pruitt. 1976. Crop water requirements. FAO Irrigation and Drainage Pap. 24. FAO, Rome, Italy.

Ferguson, N.H., and S.R. Chapman. 1993. Computer-assisted instruction for introductory genetics. J. Nat. Resour. Life Sci. Educ. 22:145-148.

Fermanian, T.W., and D.J. Wehner. 1995. A computer-based tool for introducing turfgrass species. J. Nat. Resour. Life Sci. Educ. 24:45-48.

Hanks, J., and J.T. Ritchie (ed.). 1991. Modeling plant and soil systems. Agron. Monogr. 31. ASA, CSSA, and SSSA, Madison, WI.

Hannaway, D.B., P.E. Shuler, J.P. Bolte, and M.J. Miller. 1992. Development and evaluation of LEGUME ID: A toolbook multimedia module. J. Nat. Resour. Life Sci. Educ. 21:57-61.

Kohut, C.K., M. Abley, and M.J. Dudas. 1993. MAX — an interactive computer program for teaching identification of clay minerals by x-ray diffraction. J. Nat. Resour. Life Sci. Educ. 22:169-172.

Kolb, D.A. 1984. Experiential learning: Experience as the source of learning and development. Prentice-Hall, Englewood Cliffs, NJ.

Michaels, T.E. 1993. Computer, video, and rapid-cycling plant projects in an undergraduate plant breeding course. J. Nat. Resour. Life Sci. Educ. 22:100-102.

Monteith, J.L. 1977. Climate and efficiency of crop production in Britain. Philos. Trans. R. Soc. London Ser. B 281:277-294.

Ritchie, J.T. 1972. Model for predicting evaporation from a row crop with incomplete cover. Water Resour. Res. 8:1204-1213.

Robinson, C.A., and J. Schafer. 1993. An integrated learning project in introductory soils. J. Nat. Resour. Life Sci. Educ. 22:107-110.

Salvador, R.J., D.W. Countryman, and B.E. Miller. 1995. Incorporating problem-based experiential teaching in the agriculture curriculum. J. Nat. Resour. Life Sci. Educ. 24:58-63.

Scott, H.D., and P.A. Smith. 1995. Teaching geographic information systems in a soil physics laboratory. J. Nat. Resour. Life Sci. Educ. 24:13-16.

Tanner, C.B., and T.R. Sinclair. 1983. Efficient water use in crop production: Research or re-search? In H.M. Taylor et al. (ed.) Limitations to efficient water use in crop production. ASA, CSSA, and SSSA, Madison, WI. 